\title{
The Development of Stabilised Clay-Hemp Building Material for Sustainability and Low Carbon Use
}

\author{
J.E. Oti, J.M. Kinuthia \\ School of Engineering, Faculty of Computing, Engineering and Science, University of South Wales, Pontypridd, \\ CF37 1DL, UK \\ E-mail: jonathan.oti@southwales.ac.uk (Corresponding author)
}

Received: 7 July 2020; Accepted: 31 August 2020; Available online: 5 October 2020

\begin{abstract}
This paper reports on stabilised clay-hemp building material for sustainability and low carbon use. Ground Granulated Blast-furnace Slag (GGBS) was used as a partial substitute for conventional stabiliser (lime or Portland cement) to stabilise Lower Oxford Clay (LOC) incorporating industrial hemp. The development of stabilised clay-hemp building material is expected to underpin the potential of commercial production of non-fired stabilised hemp walls, hemp blocks and hemp bricks, with a potential to offer an environmentally friendly alternative to traditional concrete, fired clay bricks and cement bricks. The parameters considered in this study are: material characterisation, unconfined compressive strength, linear expansion and cost. The 50-day linear expansion results for the test specimens showed that the maximum overall expansion rate for all the stabilised mixtures was $2 \%$. The expansion behaviour of all stabilised clay-hemp material was significantly reduced with the presence of GGBS. The cost analysis results showed that the stabilised clay-hemp material manufactured with lime - GGBS system had the lowest net present value.
\end{abstract}

Keywords: Clay masonry; Industrial hemp; Stabilised bricks; Linear expansion; Compressive strength.

\section{Introduction}

Research has shown that about $30 \%$ of the global $\mathrm{CO}_{2}$ emissions arise due to high energy usage in activities associated with the production of construction and building materials [1-4]. Much of the energy used in building materials takes place in the manufacture of a few extensively used materials which involve high temperature kiln processes, notably iron and steel, cement, clay bricks plus tiles and glass. Therefore, energy-saving strategies concentrating on low carbon building material development intended at achieving zero to negative carbon profile in building, using industrial by-product materials and low-energy additives is a development that will benefit both the present and future generations, and is a step towards more sustainable building construction [1-2].

At the present time, energy price trends are high because of the scarcity of energy sources, while energy consumption is increasing continuously worldwide. Researchers have been working hard to reduce the energy usage and $\mathrm{CO}_{2}$ emission in clay building masonry units. For example, the study by Webb [5] on mechanical pressed stabilised soil products was able to achieve a saving of at least $40 \%$ of the energy usage in a building by using stabilised soil blockwork walling, when compared to concrete blockwork. Venkatarama Reddy and Jagadish [6] studied the embodied energy of common and alternative building materials. Comparison of the energy content of steam-cured soil blocks and burnt bricks was made. Their finding showed that steam-cured soil blocks are $35 \%$ more energy efficient than burnt clay bricks. Esmeray and Atıs [7] reported on the potential of utilising sewage sludge, oven slag and fly ash for clay brick production. Sutcu et al [8] reported on the use of recycled bottom ash and fly ash wastes for eco-friendly clay brick production. Other workers [9-11] used chemical stabilisers such as cement or lime to soil to improve mechanical characteristics. Unfortunately, the addition of chemical stabilisers reduces the moisture buffering capacity and hygrothermal inertia of the material [12-13] while largely increasing the carbon footprint [14]. Labat et al [15] produced straw-clay materials with a density from 241 to $531 \mathrm{~kg} / \mathrm{m}^{3}$ and thermal conductivity from 0.071 to $0.12 \mathrm{~W} /(\mathrm{m} \mathrm{K})$. Al Rim et al [16] produced clay-cement-wood composites with a density from 370 to $1170 \mathrm{~kg} / \mathrm{m}^{3}$ and thermal conductivity from 0.08 to $0.24 \mathrm{~W} /(\mathrm{m} \mathrm{K})$. Mazhoud et al [17], reported on the mechanical properties of hemp-clay and hemp stabilised clay composites. Renouard et al [18] reported on the characterisation of ultrasonic impact on coir, flax and hemp fibres.

The key sustainability issue this paper intends to address is the current lack of significant engagement regarding the utilisation of waste from various industrial processes in the building industry. It should be noted that the use of activated slag (GGBS) with clay waste and natural fibre in building components (outside use in normal concrete 
applications) is rare in the UK. This paper and any viable building product(s) emerging from it are therefore quite innovative.

\section{Methodology}

\subsection{Materials}

The Lower Oxford Clay (LOC) used in this study was supplied by Hanson Brick Company Ltd, from their Stewartby brick plant in Bedfordshire, UK. The chemical and physical properties of the LOC are shown in Table 1. Two types of lime were used in this study. $\mathrm{L} 1$ is quicklime $(\mathrm{CaO})$ while $\mathrm{L} 2$ is hydraulic lime. Both $\mathrm{L} 1$ and $\mathrm{L} 2$ were supplied by Tŷ-Mawr Lime Ltd., Llangasty, Brecon, UK. The use of lime for clay soil stabilisation has been extensively applied in civil engineering practice such as in foundations, roadbeds, embankments and piles [19]. In practice, between 1 and 3wt.\% lime is needed for modifying soil properties and between 2 and 8 dry weight \% lime for stabilisation. Previous research work by the current research team used 6wt.\% lime [20] for stabilisation of kaolinite clay for road construction. In the current work, a maximum dosage of $4 \mathrm{wt} . \%$ lime was chosen after several laboratory trials. Ground Granulated Blast-furnace Slag (GGBS) used in this work was in compliance with BS EN 15167-1:2006 [21], it is a by-product material, generated from the iron-making industry. The Portland Cement (PC), was manufactured in accordance with BS EN 197-1:2011 [22]. Chemical and physical properties of the GGBS and PC can be seen in Table 1. The industrial hemp used in this research work was supplied by Lime Technology UK; it is a specially processed hemp for construction application that provides optimum characteristics from vapour permeability, thermal and acoustic insulation. It is produced in commercial quantities by Lhoist UK, Buxton, Derbyshire. Industrial hemp is a natural material that has the potential to reduce not only the $\mathrm{CO}_{2}$ emissions but also serve as a renewable building resource. It is the wood (fibrous) part of the hemp called hemp shiv that is used as a composite with the binder. The engineering properties of the industrial hemp used for this current work are shown in Table 2. The orientation of the mineral planes of the natural hemp in the X-ray diffractometer is shown in Figure 1. Analysis of the results shows four very strong peaks for $\mathrm{Ca}, \mathrm{SiO}_{2}, \mathrm{MAD}^{-10}$ Feldspar and Wallastonite. The quantification of the element by weight \% showed that the hemp consists mainly of $44.67 \%$ C K, 52.89\% O K, 0.09\% Mg K, 0.06\% AL K, 0.27\% Si K, 0.14\% S K, 1.20\% K K, 0.69\% Ca K and $0.19 \% \mathrm{Cu} \mathrm{K}$.

\subsection{Mix composition, sample preparation and testing}

Table 3 reports the details of the mix compositions of the stabilised cylinder specimens made using varying proportions of the two types of lime (L1 and L2) or PC blended with GGBS to stabilise the LOC and industrial hemp at $20 \%$ maximum stabiliser content. The clay content in the mix design was replaced by $2 \%$ industrial hemp shiv to improve the carbon profile of the stabilised mixture.

A series of trials for blend optimisation was conducted by the authors in their previous studies [1-2, 23-25]. At the end of the trials, optimal blending ratios (4\%L: 16\%GGBS and 4\%PC: 16\%GGBS) were adopted, based on the experience gathered by the authors in their previous research work [1-2, 26-27]. For sample preparation, it was found necessary to establish target dry density and moisture content values. Therefore, Proctor Compaction tests were carried out in accordance with BS 1924-2: 1990 [28]; for details see previous studies [1-2].

In the current research work, a much higher stabiliser dosage of $20 \%$ was used to ensure that the manufactured product is capable of carrying loads for medium-higher application, as required by most building standards and not merely for low-cost category; for detail see previous works [1-2].

Dry materials capable of producing three compacted cylindrical test specimens, each of dimensions $50 \mathrm{~mm}$ in diameter and $100 \mathrm{~mm}$ in length, were thoroughly mixed in a variable-speed Kenwood Chef Major KM250 mixer; for detail see previous works [1-2]. Immediately after mixing, the materials were compressed into cylinders, to the prescribed dry density and moisture content. A steel mould fitted with a collar was used to accommodate all the material required for one sample, and specimen compaction carried out using a hydraulic jack. After compaction, the cylinder specimens were extruded (see Figure 2), using a steel plunger. They were then weighed, wrapped in cling film and labelled before being placed in sealed plastic containers at room temperature of about $20^{\circ} \mathrm{C} \pm 2{ }^{\circ} \mathrm{C}$. The samples were then moist cured for 3, 7, 14 and 28 days.

Two cylindrical test specimens representing each of the various mix compositions were prepared for durability testing (resistance to linear expansion upon partial soaking in water). To affect partial soaking, the cling film wrapping the test specimens was carefully cut and removed at about the bottom $10 \mathrm{~mm}$, using a sharp razor. The samples were then placed on a platform in a plastic tank, with the exposed surface in contact with the platform. The specimens were then allowed to moist cure in the tank, by ensuring that water was always present below the platform upon which the test specimens were placed. To minimise evaporation and drying out of the test specimens, the plastic container was fitted with a lid which was always used to cover the container. The lid was also fitted with a digital gauge to monitor linear expansion (see Figure 3). 
Table 1. Chemical and physical properties of Lower Oxford Clay, Quicklime, Hydraulic lime GGBS and PC

\begin{tabular}{|c|c|c|c|c|c|}
\hline Oxides & LOC & L1 & L2 & GGBS & PC \\
\hline $\mathrm{CaO}$ & 6.15 & 89.2 & 66.6 & 41.99 & 63.00 \\
\hline $\mathrm{SiO}_{2}$ & 46.73 & 3.25 & 4.77 & 35.35 & 20.00 \\
\hline $\mathrm{Al}_{2} \mathrm{O}_{3}$ & 18.51 & 0.19 & 1.49 & 11.59 & 6.00 \\
\hline MgO & 1.13 & 0.45 & 0.56 & 8.04 & 4.21 \\
\hline $\mathrm{Fe}_{2} \mathrm{O}_{3}$ & 6.21 & 0.16 & 0.71 & 0.35 & 3.00 \\
\hline $\mathrm{MnO}$ & 0.07 & 0.05 & 0.08 & 0.45 & $0.03-1.11$ \\
\hline $\mathrm{S}^{2-}$ & - & $<0.01$ & $<0.01$ & 1.18 & - \\
\hline $\mathrm{SO}_{3}$ & - & 2.05 & $<0.01$ & 0.23 & 2.30 \\
\hline $\mathrm{SO}_{4}$ & - & 2.46 & $<0.01$ & - & - \\
\hline $\mathrm{CaCO}_{3}$ & - & - & - & - & - \\
\hline $\mathrm{TiO}_{2}$ & 1.13 & - & - & - & - \\
\hline $\mathrm{K}_{2} \mathrm{O}$ & 4.06 & 0.01 & 0.25 & - & - \\
\hline $\mathrm{N}_{2} \mathrm{O}$ & - & 0.02 & 0.04 & - & - \\
\hline $\mathrm{FeO}$ & 0.8 & - & - & - & - \\
\hline $\mathrm{P}_{2} \mathrm{O}_{5}$ & 0.17 & - & - & - & - \\
\hline $\mathrm{Na}_{2} \mathrm{O}$ & 0.52 & - & - & - & - \\
\hline $\mathrm{CO}_{3}$ & - & 4.00 & 3.00 & - & - \\
\hline Soluble Silica & - & 1.10 & 4.77 & - & - \\
\hline \multicolumn{6}{|l|}{ Physical Properties } \\
\hline Insoluble Residue & - & 4.1 & 2 & 0.3 & 0.5 \\
\hline Bulk Density $\left(\mathrm{kg} / \mathrm{m}^{3}\right)$ & $(1100-1250)$ & $(1150-1300)$ & 490 & 1200 & 1400 \\
\hline Relative Density & 2.63 & 2.8 & 2.4 & 2.9 & 3.1 \\
\hline Blaine fineness $\left(\mathrm{m}^{2} / \mathrm{kg}\right)$ & - & $430-1450$ & $300-1400$ & 450 & 365 \\
\hline $\mathrm{pH}$ & - & 13.9 & 12.9 & & \\
\hline Liquid Limit (LL) (\%) & 67 & - & - & - & - \\
\hline Plastic Limit (PL) (\%) & 35 & - & - & - & - \\
\hline Plasticity Index (\%) & 32 & - & - & - & - \\
\hline Colour & Grey & Off-white & White & Off-white & Grey \\
\hline Glass Content & - & - & - & $\approx 90$ & - \\
\hline
\end{tabular}

*Notation: LOC - Lower Oxford Clay; L1 - Quicklime; L2 - Hydraulic lime; GGBS - Ground Granulated Blast-furnace Slag; PC - Portland Cement.

Table 2. Engineering properties of the industrial hemp

\begin{tabular}{lc}
\hline Properties & Composition \\
\hline Flux content (\%) & 35 \\
Hiv Content (\%) & 65 \\
Length of hiv (mm) & $(8.1-15)$ \\
Width of hiv (mm) & $(0.6-1.5)$ \\
Thickness of hiv (mm) & $(2-6.5)$ \\
Bulk density $\left(\mathrm{kg} / \mathrm{m}^{3}\right)$ & 82 \\
Rate of water absorption (\%) & 117 \\
\hline
\end{tabular}

This process of moist curing was allowed to take place for the initial 7 days of specimen preparation. Thereafter, the specimens were partially immersed in water to a depth of $10 \mathrm{~mm}$ above their base by carefully increasing the water level in the tank with a siphon, thus ensuring minimal disturbance of the specimens. This process of curing after raising the water level is referred to as soaking. Linear expansion measurements were recorded during moist curing and subsequent soaking. This was done automatically, and the readings were recorded by a computer digital device every 12 hours.

The monitoring of the linear expansion measurements were completed on a daily basis until no further significant expansion was observed. Both the moist-curing and soaking environments were within sealed systems in order to reduce the availability of carbon dioxide that would otherwise cause carbonation of the lime in the hydrating system, which may reduce the amount of lime available for pozzolanic reaction. For soaking, deionised water was used to avoid specimen contamination from metallic or other ion species in the water.

A total of 126 test cylinder specimens were prepared, 108 for strength testing and 18 for linear expansion tests. At the end of the curing period, three samples per mix proportion were tested for compressive strength at an age of 3, 7, 14 and 28 days in accordance with BS 1924-2: 1990 [28], using a Hounsfield testing machine at a compression loading rate of $1 \mathrm{~mm} / \mathrm{min}$. Two samples per mix proportion at moisture content of 27, 30 and $33 \%$ 
were used to determine the linear expansion behaviour of the compacted cylinders during moist curing and during subsequent soaking in de-ionised water.

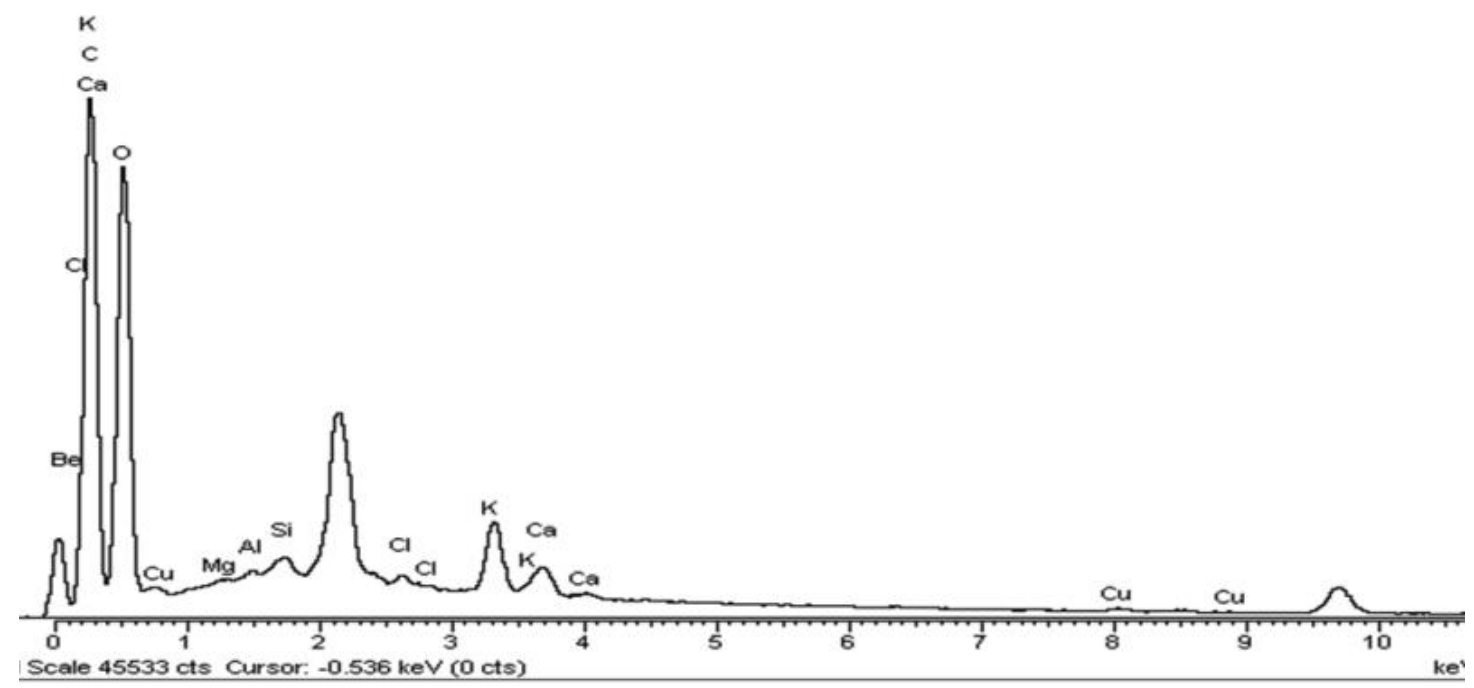

$\left(\mathrm{C}=\mathrm{Ca}, \mathrm{O}=\mathrm{SiO}_{2}, \mathrm{Mg}=\mathrm{MgO}, \mathrm{Al}=\mathrm{Al}_{2} \mathrm{O}_{3}, \mathrm{Si}=\mathrm{SiO}_{2}, \mathrm{Cl}=\mathrm{KCl}, \mathrm{K}=\mathrm{MAD}-10\right.$ Feldspar, $\mathrm{Ca}=$ Wollastonite,$)$

Figure 1. $\mathrm{X}$ - Ray diffraction of the hemp fibre

Table 3. Mix composition of the blended hemp - LOC mixture (material for one cylindrical test specimen)

\begin{tabular}{lccccccccc}
\hline Stabilisers & Mix Code & $\begin{array}{c}\text { Moisture } \\
\text { Content }\end{array}$ & $\begin{array}{c}\text { Lime } \\
\text { L1 }\end{array}$ & $\begin{array}{c}\text { Lime } \\
\text { L2 }\end{array}$ & PC & GGBS & LOC & Hemp & Water \\
\hline L1-GGBS & 4\%L1:16\%GGBS & $27 \%$ & 10.5 & & 0 & 42 & 257.25 & 5.25 & 85 \\
L2-GGBS & 4\%L2:16\%GGBS & $27 \%$ & 0 & 10.5 & 0 & 42 & 257.25 & 5.25 & 85 \\
PC-GGBS & 4\%PC:16\%GGBS & $27 \%$ & 0 & 0 & 10.5 & 42 & 257.25 & 5.25 & 85 \\
L1-GGBS & 4\%L1:16\%GGBS & $30 \%$ & 10.5 & & 0 & 41 & 251.86 & 5.14 & 92 \\
L2-GGBS & 4\%L2:16\%GGBS & $30 \%$ & 0 & 10.5 & 0 & 41 & 251.86 & 5.14 & 92 \\
PC-GGBS & 4\%PC:16\%GGBS & $30 \%$ & 0 & 0 & 10.5 & 41 & 251.86 & 5.14 & 92 \\
L1-GGBS & 4\%L1:16\%GGBS & $33 \%$ & 10.5 & 0 & 0 & 40.1 & 245.6 & 5 & 99.3 \\
L2-GGBS & 4\%L2:16\%GGBS & $33 \%$ & 0 & 10.5 & 0 & 40.1 & 245.6 & 5 & 99.3 \\
PC-GGBS & 4\%PC:16\%GGBS & $33 \%$ & 0 & 0 & 10.5 & 40.1 & 245.6 & 5 & 99.3 \\
\hline
\end{tabular}

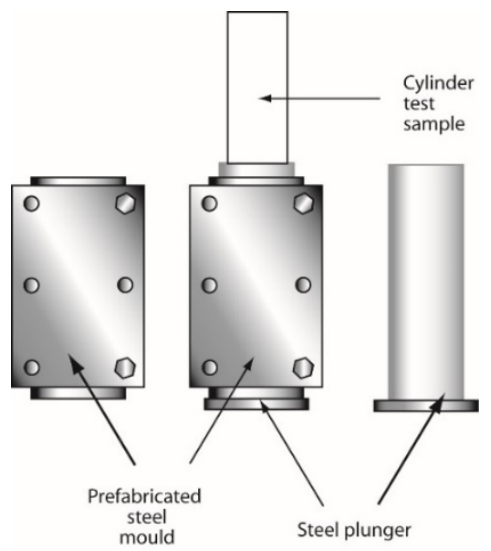

Figure 2. Steel mould (extension collar not shown) and the extruded cylindrical test specimen

\section{Result and discussion}

\subsection{Strength development of the Lime-GGBS and PC-GGBS stabilised systems}

The compressive strength results of L1 - GGBS, L2 - GGBS and PC - GGBS cylinder specimens compacted at 27,30 and $33 \%$ moisture content and cured at room temperature of about $20^{\circ} \mathrm{C} \pm 2{ }^{\circ} \mathrm{C}$ for up to 28 days are 
shown in Figure 4a-d. It was observed that at the early curing ages (3-day), the L2 - GGBS and PC - GGBS blends exhibited lower strength values than that of L1 - GGBS.

The highest strength value obtained at the end of the 3-day moist curing was $857 \mathrm{kN} / \mathrm{m}^{2}$ at $27 \%$ compaction moisture content. Similar trends were observed at 7 and 14-days curing age (the L1 - GGBS blend stabilised cylinder specimens tending to have higher strength value at all compaction moisture content).

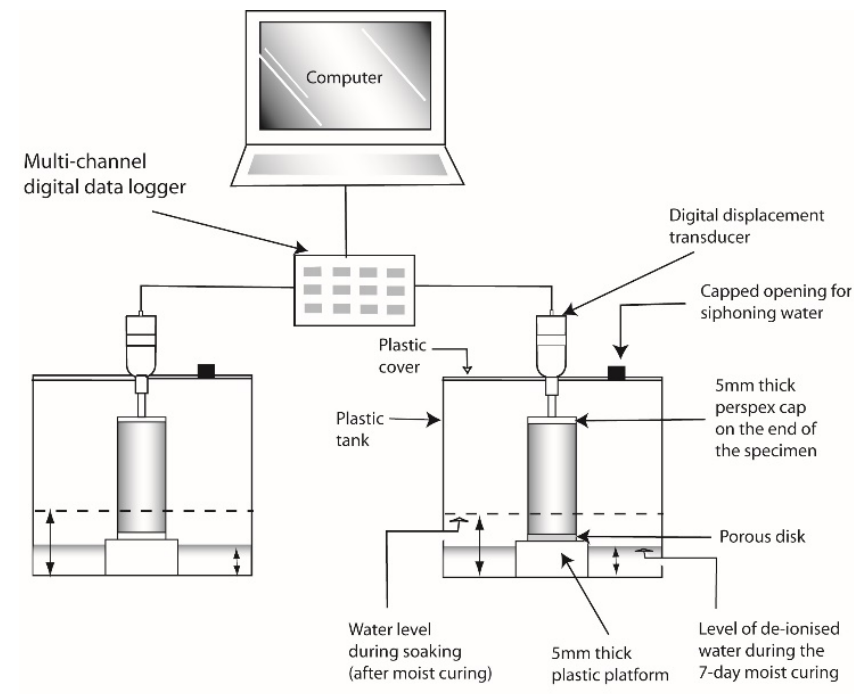

Figure 3. A 64-channel data logger (MX2000 VJ Tech) for recording linear expansion measurements
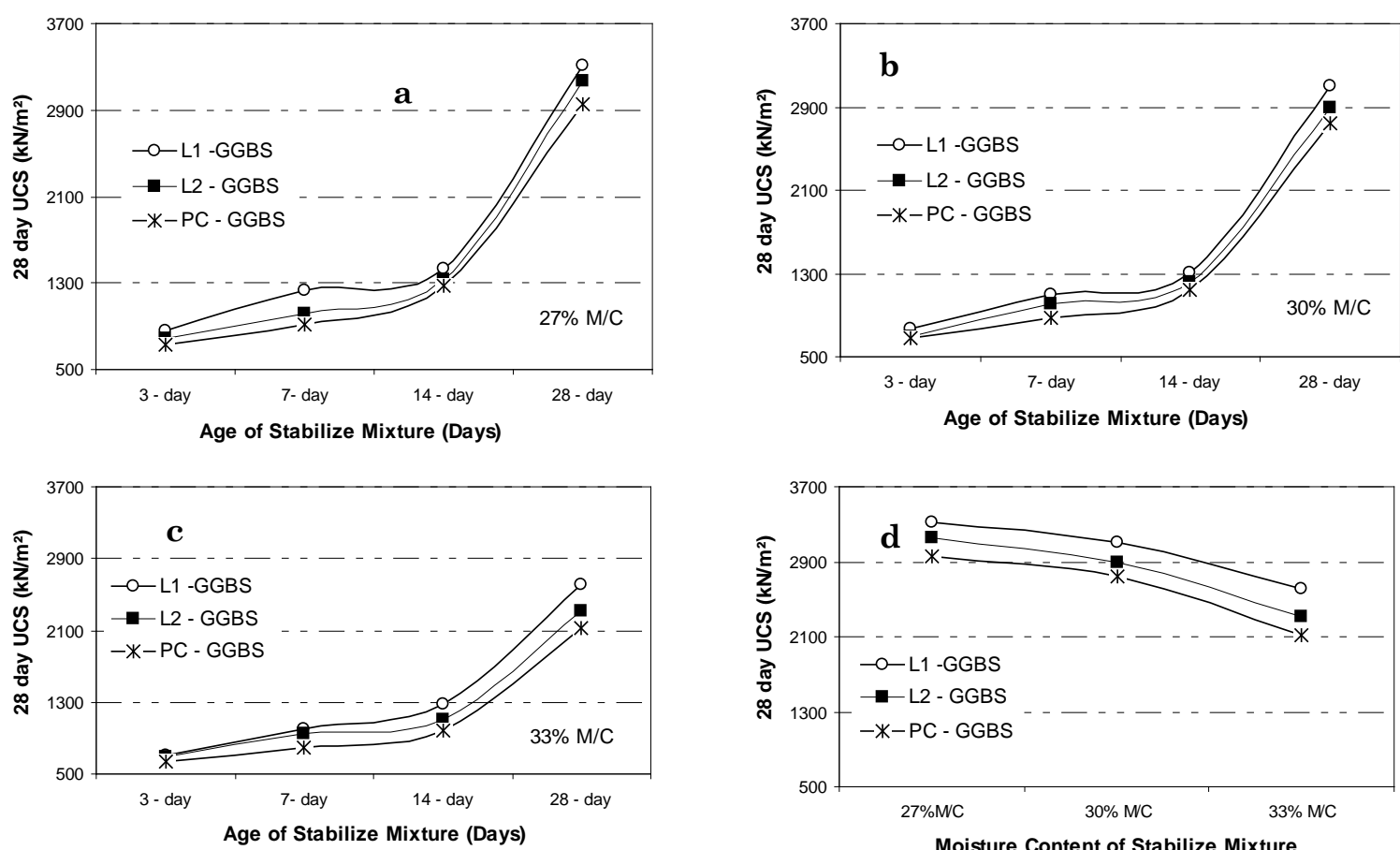

Figure 4(a-d). Strength development of various stabilised systems

At the end of the 28-day moist curing period, there was a significant improvement in the strength values of all compacted cylinder specimen at 27, 30 and 33\% compaction moisture contents. As observed previously (3, 7 and 14-days), the highest strength value this time was $3,316 \mathrm{kN} / \mathrm{m}^{2}$, again this value was for the L1 - GGBS mixture. It is interesting to note that previous work (Kinuthia and Oti, 2012) with mixes without hemp, indicate that there is significant strength gain with age up to 28 days for the mixtures stabilised with lime and GGBS (L1-GGBS and L2-GGBS), the highest strength of $3,200 \mathrm{kN} / \mathrm{m}^{2}$ was observed for mix L1-GGBS at $27 \%$. The gain in unconfined compressive strength with age was lower for the mixture with PC and GGBS (PC-GGBS) at all compaction 
moisture contents. The lime-activated GGBS stabiliser has significantly higher influence in strength than the equivalent PC-based system as observed from the results and the addition of hemp has higher influence in strength development at the end of the 28-day moist curing period.

The overall performance of the two different limes and PC, each blended with GGBS, shows that when the compaction moisture content was increased from $27 \%$ up to $33 \%$, the strength values of the cylinder specimen for all blended stabilised mixture was significantly reduced.

The mechanism for the hydration cycle may be complex and can be difficult to explain in detail. But in general, one major activity that takes place is the modification of the soil as a result of ion exchange. The other activity that takes place during the hydration process is the solidification of the clay soil as a result of pozzolanic reaction. The difference in the hydration reactions between lime and GGBS may lead to a difference in the microstructure of the stabilised system. The reactions that take place may be very complex, for example the calcium oxide $(\mathrm{CaO})$ from lime or GGBS may react with the clay soil particles to form calcium hydroxide $\mathrm{Ca}(\mathrm{OH})_{2}$. The system may have high concentrations of calcium ion (Ca2+) and hydroxide ions $(\mathrm{OH}-)$. Then an exchange of cation may occur in the whole system, during this process sodium ion $\left(\mathrm{Na}^{+}\right)$and potassium $\left(\mathrm{K}^{+}\right)$is displaced [1-2].

The replacement of monovalent sodium and potassium ions by divalent calcium ion during the ion exchange process may induce changes in the soil properties within the first hour of the hydration process. The concentration of divalent calcium ions induces the flocculation of the clay colloids which then transform the plastic soil particles to a granular state, while the monovalent sodium and potassium ions enhances dispersion. The sodium ion $\left(\mathrm{Na}^{+}\right)$ and potassium $\left(\mathrm{K}^{+}\right.$in the lime and GGBS potentially increase the exchangeable cation in the entire blended system [1-2]. This may be another reason for the variation in strength values in the stabilised mixtures. The increase in compaction moisture content of the compacted cylinder specimens from 27 to 33\% produced a significant reduction in strength values, observed with all the stabiliser blends, at all mix proportions at the optimal blending ratio of $4 \%: 16 \% \mathrm{~L} / \mathrm{PC}: \mathrm{GGBS}$.

\subsection{Linear expansion}

Figure 5a-f illustrates the expansion behaviour during moist curing and subsequent soaking of the various samples (L1 - GGBS, L2 - GGBS, and PC - GGBS) at 27, 30 and 33\% compaction moisture content. The linear expansions during the 7-day moist curing observed so far suggest very low expansion for all the stabiliser blends, within the range of $0-0.7 \%$. No noticeable shrinkage was noted.

The linear expansion during soaking of the blended cylinder specimens suggest relatively more rapid expansion upon soaking, with the highest recorded expansion being about 1.65\%, recorded for the L2 - GGBS blend at 33\% compaction moisture content. The least linear expansion was $1.06 \%$, observed from the specimens made using the PC - GGBS blend at 27\% compaction moisture content. Interestingly, this stabiliser blend recorded the least strength development.

The total overall expansion rate of the samples $(0-1.65 \%)$ at the compaction moisture content of 27,30 and $33 \%$ is within the acceptable limit for the durability of stabilised clay masonry units. The total maximum 50-day linear expansion is summarised in Figure 6. It is interesting to note that in previous work [1-2, 23-25] with mixes without hemp, the blend made with quicklime (L1 - GGBS) showed the highest expansive behaviour, with the highest recorded expansion magnitude of about $1.6 \%$ at $33 \%$ compaction moisture content. The lowest linear expansion of $0.9 \%$ was observed from the blended optimised cylinder specimens made using the PC - GGBS blend. The addition of hemp has no significant influence on the rate of expansion.

Swelling and linear expansion of stabilised clay soil is common and is known to be associated with the formation of a colloidal product (gel intermixed with ettringite), which forms on the surface of the clay particles during curing. When in a saturated condition, ettringite grows and develops from this colloidal product [1-2]. It has a capability of imbibing large amounts of water and dramatically increases the swelling potential of the stabilised soil, especially if lime is used as a stabiliser [1-2]. However, the introduction of a cementing agent, such as PC or GGBS, modifies the chemical interaction of the clay-lime system, thereby altering the types of reactions and thus potentially altering any disruptions that the reaction by-product may cause. It is therefore not surprising that the test specimens made using PC-GGBS expanded much less relative to those stabilised using a lime-GGBS blended binder [1-2].

Over the 50-day linear expansion observation period, all the samples either attained terminal linear expansion or continued to expand at a negligible rate. The linear expansion started during the 7-day curing period and increased when the specimens were soaked in water after the 7-day moist-curing period. This expansion was more stable for the rest of the 36 days of soaking. The PC - GGBS blended LOC samples recorded significantly lower expansion values compared with the lime - GGBS stabilised LOC. The overall reduction in linear expansion is likely to be due to the formation of cementitious products [1-2]. The cementitious gels cement the soil particles together and enable them to resist the considerable swelling pressures which can be generated when ettringite forms in the presence of water [1-2]. The hydration of the PC - GGBS stabiliser blend is much more rapid 
compared with the pozzolanic reaction of lime - GGBS with clay. This hydration reaction is known to consume lime [1-2].
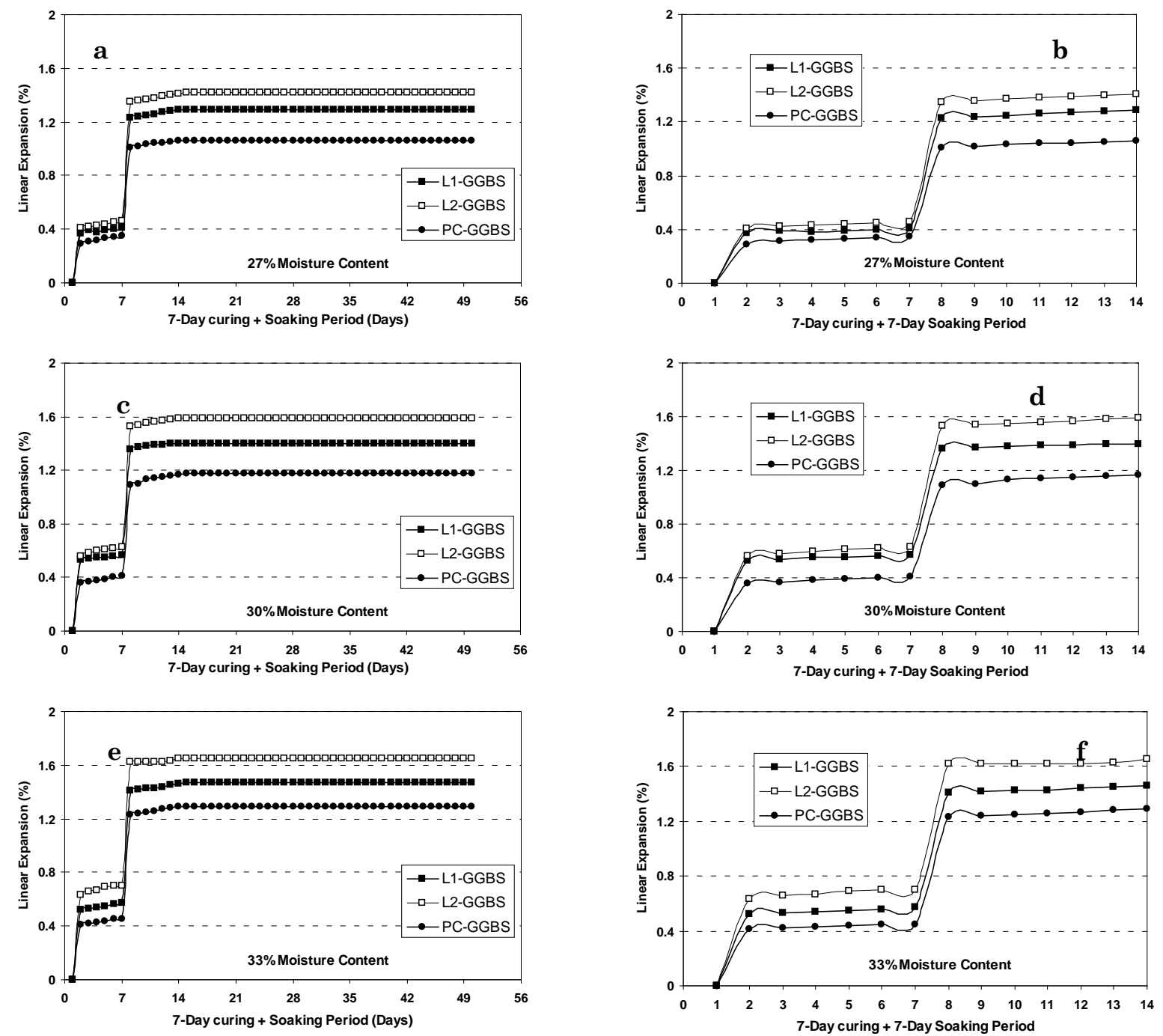

Figure 5(a-f). Linear expansion measurements during moist curing (7 days) and subsequent soaking of the stabilised cylinder specimens, made at 27-33 \% compaction moisture content.

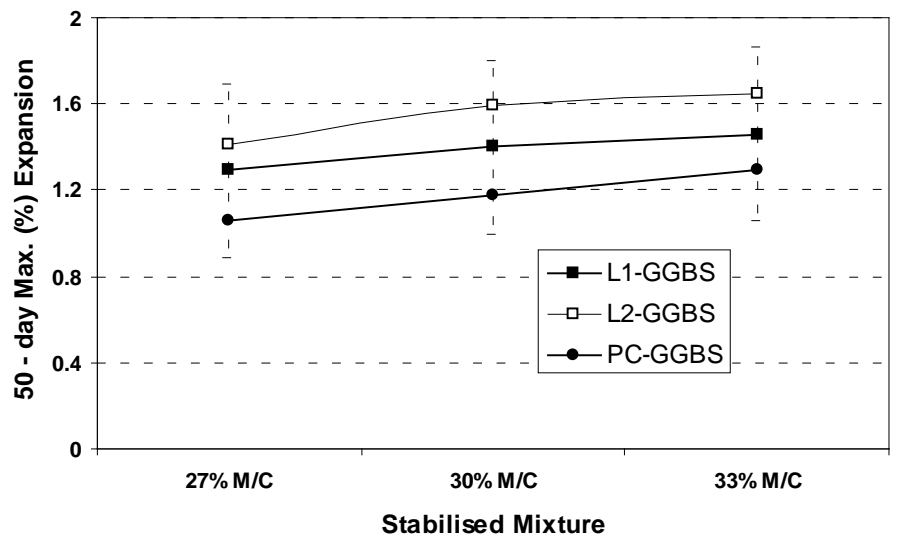

Figure 6. Total (maximum) 50-day linear expansion measurements for moist curing (7 days) and subsequent soaking of the stabilised cylinder specimens, made at $27-33 \%$ compaction moisture content 
One possible explanation why the lime - GGBS stabilised test specimens expanded relatively more compared with the PC - GGBS specimens is perhaps because of relatively more ettringite formation during the hydration process in the lime - GGBS blended matrix, with the ettringite subsequently imbibing large quantities of water, leading to expansion. Other hydration products may also fill the void space of the stabilised system, thus enhancing both strength and volume stability upon subsequent soaking [1-2, 23-25; 29].

The fact that higher strength magnitudes in the lime - GGBS system were observed and it is the same system which expanded the most suggests that volume stability is a sensitive balance between void space and cementation. GGBS may also play the role of diluting the stabilised system, thus reducing the amount of expansive products in the pore space and also increasing the effective water-to-stabiliser ratio. This would enable a greater degree of $\mathrm{CaO}$ hydration [1-2]. This minimises any possible disruption to the hardened product and the overall expansion may be reduced. In addition to the above hypotheses, GGBS may also mitigate the expansion by providing a surface upon which lime can be adsorbed and subsequently interact by activating the hydration process with the enhanced $\mathrm{pH}$ environment [1-2; 29].

\subsection{Laboratory stabilised clay-hemp brick manufacture}

In order to establish the viability of the transition from the laboratory cylinder specimens produced elsewhere to actual brick production, a full-scale steel mould was fabricated with a view to producing full-sized bricks for further testing, rather than using cylinder test specimens. This enabled laboratory-scale production of full-sized building bricks of dimensional configuration of 215 x 102.5 × 65mm using the L1 - GGBS, L2 - GGBS, and PC - GGBS mixtures at 27\% moisture content. The results were an immediate success, as demonstrated in Figures 7 (full-sized clay bricks made at laboratory scale).

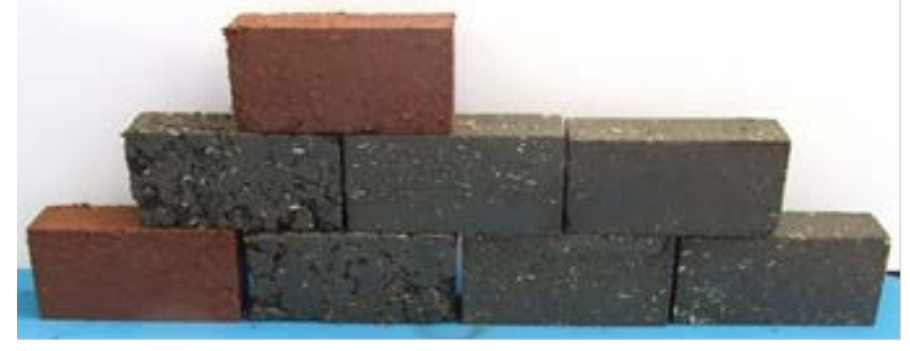

Figure 7. Freshly prepared clay-hemp bricks using L1 - GGBS, L2 - GGBS, and PC - GGBS mixtures

\subsection{Cost analysis of the stabilised clay-hemp brick}

The identification of a potential market for all the stabilised clay-hemp brick types (L1 - GGBS, L2 - GGBS, and PC - GGBS) manufactured at 27\% moisture content, could be an influential factor for a successful unfired clay masonry brick development programme. A cost-benefit analysis was conducted for all the stabilised clayhemp brick types to provide a protocol for measuring the efficient allocation of resources. The overall aim is to provide the researchers/planner with a set of values that are useful to determine the feasibility of the stabilised clay-hemp brick project from an economic standpoint. To calculate the payback period for all the stabilised clayhemp brick types, the energy cost was determined. Since the thermal load on is cumulative, the energy used (E) is calculated by the following equation [30]:

$$
E=\frac{0.024 \times D}{R \times C} k W h / m^{2}
$$

where $\mathrm{D}$ is the degree-days of the location $(\mathrm{D}=2,185)$; $R$ is the thermal resistance of the brick sample, and $C$ is the coefficient of thermal performance of the system $(C=2.16)$. The total discounted cost or a net present value (NPV) per square metre of brick surface area is calculated using the following equation:

$$
N P V=E * P W F * E C+B C\left(£ / m^{2}\right)
$$

where $\mathrm{E}$ is the annual energy consumption, EC is the energy cost (8 pence/kWh), PWF is the present worth factor and $\mathrm{BC}$ is the cost stabilised clay-hemp brick. The present worth factor, PWF, is calculated using the equation

$$
\begin{aligned}
& P W F=\frac{1}{i-e}\left\langle 1-\left(\frac{1-e}{1-i}\right)^{n}\right\rangle \text { for } e \neq i \\
& P W F=n \cdot(i+e) \text { for } e=i
\end{aligned}
$$


where $e$ is the energy inflation rate (3.5\%); $i$ is the discount rate (6\%) and $n$ is the lifetime of the stabilised clayhemp brick (30 years). The inflation rate, the discounted rate and the present worth factor are presented in Table 4 and it can be seen that the values are the same for all brick types.

The cost analysis along with the energy use and the net present value for all the stabilised clay-hemp bricks types (L1 - GGBS, L2 - GGBS, and PC - GGBS) are presented in Table 5. It can be seen that the stabilised clayhemp brick manufactured with the PC - GGBS system has the highest net present value while the lowest net present value was observed for stabilised clay-hemp brick manufactured with the LG1 - GGBS system. Similar trends were observed for energy use. For the brick cost, the highest brick cost was observed for the stabilised clayhemp brick manufactured with LG1 - GGBS system, while the lowest brick cost was obtained for the stabilised clay-hemp brick manufactured with the PC - GGBS system. Since the simple payback analysis only gives the recovery period of an additional investment, it ignores the influence of discount rate and cost escalation. Net present value analysis is the correct approach for economic analysis as it takes into account the life period of the stabilised clay-hemp brick, time value of money (discount rate) and energy escalation cost. The net present value analysis shows that the stabilised clay-hemp brick manufactured with the LG1 - GGBS system is the most effective of all the brick types as it has the lowest net present value of $61.17 £ / \mathrm{m}^{2}$.

Table 4. The inflation and discount values of the stabilised clay-hemp bricks

\begin{tabular}{lccccc}
\hline \multicolumn{1}{c}{ Brick Type } & $\begin{array}{c}\mathbf{e} \\
\mathbf{\%}\end{array}$ & $\begin{array}{c}\mathbf{i} \\
\mathbf{\%}\end{array}$ & $\begin{array}{c}\mathbf{n} \\
\text { years }\end{array}$ & PWF & $\begin{array}{c}\text { EC } \\
\text { pence/kWh }\end{array}$ \\
\hline L1 - GGBS & 3.5 & 6.0 & 30 & 0.0962 & 8.0 \\
L2 - GGBS & 3.5 & 6.0 & 30 & 0.0962 & 8.0 \\
PC - GGBS & 3.5 & 6.0 & 30 & 0.0962 & 8.0 \\
\hline
\end{tabular}

*Note: $\mathrm{e}=$ inflation rate; $\mathrm{i}=$ discount rate; $\mathrm{n}=$ lifetime of the unfired bricks.

Table 5. The net present values of the stabilised clay-hemp bricks

\begin{tabular}{lcccccc}
\hline Brick Type & $\begin{array}{c}\mathbf{R} \\
\left(\mathbf{m}^{\mathbf{2}} \mathbf{K}^{-\mathbf{1}} \mathbf{W}^{-\mathbf{1}}\right)\end{array}$ & $\begin{array}{c}\mathbf{D} \\
\mathbf{D e g r e e - d a y}\end{array}$ & $\mathbf{C}$ & $\begin{array}{c}\mathbf{E} \\
\mathbf{k W h} / \mathbf{m}^{\mathbf{2}}\end{array}$ & $\begin{array}{c}\mathbf{B C} \\
\mathbf{E} / \mathbf{m}^{\mathbf{2}}\end{array}$ & $\begin{array}{c}\mathbf{N P V} \\
\mathbf{E} / \mathbf{m}^{\mathbf{2}}\end{array}$ \\
\hline L1 - GGBS & 0.3625 & 2,185 & 2.16 & 66.95 & 9.65 & 61.17 \\
L2 - GGBS & 0.3471 & 2,185 & 2.16 & 69.92 & 9.35 & 63.16 \\
PC - GGBS & 0.3375 & 2,185 & 2.16 & 71.91 & 8.75 & 64.09 \\
\hline
\end{tabular}

*Note: $\mathrm{R}$ = the thermal resistance of the unfired clay bricks; $\mathrm{D}$ = Degree-days; $\mathrm{C}$ = Coefficient of thermal conductivity; $\mathrm{E}$ $=$ Energy used; $\mathrm{BC}=$ Cost of the unfired clay bricks.

\section{Conclusions}

The results obtained so far suggest the following conclusions.

There is potential for using blended binders for the manufacture of unfired clay materials within the building construction industry. The lime - GGBS blends in particular showed promise. Using Lower Oxford Clay and industrial hemp as the target stabilisation materials, the cylinder test specimen made with PC - GGBS blends tended to achieve lower strength values compared with the different lime - GGBS blends. The strength characteristics of the unfired bricks were improved with the presence of the lime and GGBS which act as a bond on the soil particles.

The lime and GGBS offers other benefits in enhancing the all-round performance with volume stability and overall durability. The expansive behaviour upon moist curing and soaking in water of the stabilised clay-hemp mixture were within the acceptable limit for the durability of stabilised clay masonry units.

The outcome of the cost analysis shows that the stabilised clay-hemp bricks manufactured with the LG1-GGBS system is the most effective among the bricks studied as it has the lowest net present value.

\section{References}

[1] Oti JE, Kinuthia JM, Bai J. Unfired clay masonry bricks incorporating slate waste. Proceedings of the Institution of Civil Engineers -Waste and Resource Management. 2010; 163(1): 17-27.

[2] Oti JE. The development of unfired clay building materials for sustainable building construction. [PhD Thesis]. University of Glamorgan, Pontypridd, UK; 2010.

[3] Biswas WK. Carbon footprint and embodied energy consumption assessment of building construction works in Western Australia. International Journal of Sustainable Built Environment. 2014; 3(2): 179-186.

[4] UNEP. Buildings and climate change - Summary for decision-makers. UNEP DTIE, Sustainable Consumption \& Production Branch, 15 Rue de Milan, 75441 Paris CEDEX 09, France. 2009. 
[5] Webb DJT. Stabilised soil and the built environment. Renewable Energy.1994; 5 (5-8): 1066-1080.

[6] Reddy BV, Jagadish KS. Embodied energy of common and alternative building materials and technologies. Energy and Buildings. 2003;35(2):129-137.

[7] Esmeray E, Atıs M. Utilization of sewage sludge, oven slag and fly ash in clay brick production. Construction and Building Materials. 2019;194:110-121.

[8] Sutcu M, Erdogmus E, Gencel O, Gholampour A, Atan E, Ozbakkaloglu T. Recycling of bottom ash and fly ash wastes in eco-friendly clay brick production. Journal of Cleaner Production. 2019;233:753-764.

[9] Kariyawasam KK, Jayasinghe C. Cement stabilized rammed earth as a sustainable construction material. Construction and Building Materials. 2016;105:519-527.

[10] Khadka B, Shakya M. Comparative compressive strength of stabilized and un-stabilized rammed earth. Materials and Structures. 2016;49(9):3945-3955.

[11] Dao K, Ouedraogo M, Millogo Y, Aubert JE, Gomina M. Thermal, hydric and mechanical behaviours of adobes stabilized with cement. Construction and Building Materials. 2018;158:84-96.

[12] McGregor F, Heath A, Fodde E, Shea A. Conditions affecting the moisture buffering measurement performed on compressed earth blocks. Building and Environment. 2014;75:11-18.

[13] Arrigoni A, Grillet AC, Pelosato R, Dotelli G, Beckett CT, Woloszyn M, Ciancio D. Reduction of rammed earth's hygroscopic performance under stabilisation: an experimental investigation. Building and Environment. 2017;115:358-367.

[14] Worrell E, Price L, Martin N, Hendriks C, Meida LO. Carbon dioxide emissions from the global cement industry. Annual Review of Energy and the Environment. 2001;26(1):303-329.

[15] Labat M, Magniont C, Oudhof N, Aubert JE. From the experimental characterization of the hygrothermal properties of straw-clay mixtures to the numerical assessment of their buffering potential. Building and Environment. 2016;97:69-81.

[16] Al Rim K, Ledhem A, Douzane O, Dheilly RM, Queneudec M. Influence of the proportion of wood on the thermal and mechanical performances of clay-cement-wood composites. Cement and Concrete Composites. 1999;21(4):269-276.

[17] Mazhoud B, Collet F, Pretot S, Lanos C. Mechanical properties of hemp-clay and hemp stabilized clay composites. Construction and Building Materials. 2017;155:1126-1137.

[18] Renouard S, Hano C, Doussot J, Blondeau JP, Lainé E. Characterization of ultrasonic impact on coir, flax and hemp fibers. Materials Letters. 2014;129:137-141.

[19] Boardman DI, Glendinning S, Rogers CD. Development of stabilisation and solidification in lime-clay mixes. Geotechnique. 2001;51(6):533-543.

[20] Oti JE, Kinuthia JM. Stabilised unfired clay bricks for environmental and sustainable use. Applied Clay Science. 2012;58:52-59.

[21] BS EN 15167-1. Ground granulated blast furnace slag for use in concrete, mortar and grout. Part 1: Definitions, specifications and conformity criteria. 2006.

[22] BS EN 197-1. Cement. Part 1: Composition, specifications and conformity criteria for common cements. 2011.

[23] Oti JE, Kinuthia JM. Stabilised unfired clay bricks for environmental and sustainable use. Applied Clay Science. 2012;58:52-59.

[24] Kinuthia JM, Oti JE. Designed non-fired clay mixes for sustainable and low carbon use. Applied clay science. 2012;59:131-139.

[25] Oti JE, Kinuthia JM, Bai J. Engineering properties of unfired clay masonry bricks. Engineering Geology. 2009;107(3-4):130-139.

[26] Oti JE, Kinuthia JM, Bai J. Using slag for unfired-clay masonry-bricks. Proceedings of the Institution of Civil Engineers-Construction Materials. 2008;161(4):147-155.

[27] Oti JE, Kinuthia JM, Bai J. Developing unfired stabilised building materials in the UK. Proceedings of the Institution of Civil Engineers-Engineering Sustainability. 2008;161(4);211-218.

[28] BS 1924-2: 1990 - British Standards Institute. Stabilised materials for civil engineering purposes - Part 2: Methods of test for cement-stabilised and lime- stabilised materials.

[29] Oti JE, Kinuthia JM, Bai J. Development of innovative low carbon clay bricks. Proceedings of the 2nd International Conference on Learning from Earthen Architecture in Climate Change (Kerpic”08), Cyprus International University, Lefkosa Northern Cyprus. 2008. p.291-297.

[30] Al-Hadhrami LM, Ahmad A. Assessment of thermal performance of different types of masonry bricks used in Saudi Arabia. Applied Thermal Engineering. 2009;29(5-6):1123-1130.

(C) 2020 by the author(s). This work is licensed under a Creative Commons Attribution 4.0 International License (http://creativecommons.org/licenses/by/4.0/). Authors retain copyright of their work, with first publication rights granted to Tech Reviews Ltd. 